\title{
OPEN Surface microstructures developed on polished quartz crystals embedded in wet quartz sand compacted under hydrothermal conditions
}

\begin{abstract}
Peter M. Schutjens ${ }^{1}$, Christopher J. Spiers ${ }^{2}$ \& André Rik Niemeijer ${ }^{2 \bowtie}$
Intergranular pressure solution plays a key role as a deformation mechanism during diagenesis and in fault sealing and healing. Here, we present microstructural observations following experiments conducted on quartz aggregates under conditions known to favor pressure solution. We conducted two long term experiments in which a quartz crystal with polished faces of known crystallographic orientation was embedded in a matrix of randomly oriented quartz sand grains. For about two months an effective axial stress of $15 \mathrm{MPa}$ was applied in one experiment, and an effective confining pressure of $28 \mathrm{MPa}$ in the second. Loading occurred at $350^{\circ} \mathrm{C}$ in the presence of a silica-saturated aqueous solution. In the first experiment, quartz sand grains in contact with polished quartz prism (1010) faces became ubiquitously truncated against these faces, without indenting or pitting them. By contrast,

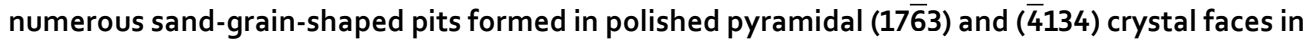
the second experiment. In addition, four-leaved and (in some cases) three-leafed clover-shaped zones of precipitation formed on these prism faces, in a consistent orientation and pattern around individual pits. The microstructures observed in both experiments were interpreted as evidence for the operation of intergranular pressure solution. The dependence of the observed indentation/truncation microstructures on crystal face orientation can be explained by crystallographic control of stressinduced quartz dissolution kinetics, in line with previously published experimental and petrographic data, or possibly by an effect of contact orientation on the stress-induced driving force for pressure solution. This should be investigated in future experiments, providing data and microstructures which enable further mechanism-based analysis of deformation by pressure solution and the effect of crystallographic control on its kinetics in quartz-rich sands and sandstones.
\end{abstract}

Intergranular pressure solution (IPS) is a deformation mechanism whereby interfacial and diffusive mass transfer occurs through an aqueous phase present within grain boundaries and pores, facilitating compaction creep of porous rocks and deviatoric creep of dense rock materials ( $\mathrm{se}^{1}$ for a review). The process is driven by an effective stress acting on fluid-infiltrated granular aggregates ${ }^{2}$. Stress concentrations at grain contacts induce gradients in chemical potential within the solid and thus create local dis-equilibrium between the solid and the solute in solution. Dissolution occurs preferentially where the chemical potential of stressed solid is higher than that of the solute in solution; precipitation occurs where the chemical potential of the solute in solution is higher than that of the solid. In a system where there is no long range advective transport of solute in or out of the system by flowing pore fluid, the gradient in solute concentration leads to material diffusion from the high-stress sites of dissolution (the grain contacts) to the low-stress sites of precipitation, through the fluid-infiltrated grain-to-grain contacts and the fluid in the pores. Dissolution and diffusion of material from highly stressed grain contacts to contacts supporting lower stress, or to free pore walls, produces a change in grain shape and a relative displacement of neighboring grains centers, which leads to creep deformation and/or compaction, depending on stress state and porosity. The process is variously termed intergranular pressure solution (IPS), pressure solution, pressure solution creep, or fluid-assisted diffusion creep.

${ }^{1}$ Shell Global Solutions International B.V., Rijswijk, The Netherlands. ${ }^{2}$ HPT Laboratory, Faculty of Geosciences, Utrecht University, Utrecht, The Netherlands. ${ }^{\varpi}$ email: a.r.niemeijer@uu.nl 


\begin{tabular}{|l|l|l|l|}
\hline Experiment & Geometry & ${\text { Dimensions of polished faces }(\mathbf{m m})^{\mathbf{1}}}^{\text {Crystallographic orientation }^{2}}$ \\
\hline QC 13 & Cylinder at bottom of sand sample & $\Phi=10, \mathrm{~h}=1.6-1.8$ & $(10 \overline{1} 0)$ \\
\hline \multirow{2}{*}{ QC 14 } & $\begin{array}{l}\text { Quarter of a cylinder } \\
\text { Face A } \\
\text { Face B }\end{array}$ & $\begin{array}{l}\mathrm{h}=9.0, \mathrm{w}=2.0 \\
\mathrm{~h}=9.0, \mathrm{w}=3.0\end{array}$ & $\begin{array}{l}(1 \overline{6} 3) \lambda=203, \theta=64 \\
(\overline{4} 314) \lambda=315, \theta=48\end{array}$ \\
\hline
\end{tabular}

Table 1. Geometry of experiment and dimensions and orientation of polished faces on single crystals of quartz. ${ }^{1} \varphi=$ diameter, $\mathrm{h}=$ height, $\mathrm{w}=$ width. ${ }^{2} \lambda=$ azimuth, $\theta=$ dip, $\lambda=0^{\circ}:$ crystallographic [1010] direction, $\theta=0^{\circ}$ : crystallographic [0001] direction.

It is generally accepted that characteristic mass removal microstructures, like grain-to-grain indentations, contact truncations and sutured grain contacts in rocks, are the result of IPS ( $\mathrm{see}^{1}$ for a review). Because of its effectiveness in reducing intergranular porosity, IPS is considered one of the main factors controlling the geologic evolution of porosity and permeability, and hence capacity and productivity of hydrocarbon and geothermal reservoir sandstones ${ }^{3,4}$ as well as the capacity and injectivity of potential $\mathrm{CO}_{2}$ or $\mathrm{H}_{2}$ storage reservoirs ${ }^{5}$. Alongside reducing porosity, IPS tends to increase the average surface area of grain contacts, which enhances the loadbearing capacity (failure strength) and reduces (poro-elastic) compressibility. The extent (i.e. the "intensity") of IPS in sandstones appears to depend on thermal maturity/history, grain size (e.g. $\left.{ }^{6}\right)$ and crystallographic orientation with respect to dissolution contact surface (e.g. ${ }^{7,8}$ ), as well as on a number of other factors which are still poorly understood. These include pore fluid composition, concentrations of clays and micas in grain contacts and pores $^{9,10}$ and the presence of grain contact cement phases. Equally important is the role of IPS in controlling the compaction, cementation and hence healing and sealing behavior of fault gouges formed in faults cutting both clastic sedimentary sequences and granitic basement (e.g. ${ }^{11,12}$ ). IPS has also been shown to be a key mechanism controlling the frictional behavior of fault gouges and in particular the unstable shearing behavior involved in the nucleation of both natural and induced earthquakes ${ }^{13}$.

The above interest in IPS processes has provided an incentive for the development of numerous microphysically-based constitutive equations addressing compaction and deformation by IPS creep (e.g. ${ }^{14-17}$ ) as well as its effects on fault gouge compaction and shear ${ }^{13}$. Two broad classes of grain scale mechanisms have been proposed. The first is the so-called marginal dissolution process ${ }^{18}$, envisaged to involve progressive undercutting of grain contacts (Supplementary Fig. 1, top). The second is grain boundary diffusion (e.g. ${ }^{17}$ ), involving dissolution and diffusion of material through a very thin (adsorbed) fluid film (Supplementary Fig. 1, middle) or an intergranular fluid-filled island-channel network (Supplementary Fig. 1, bottom), with the additional possibility of microcracking at grain contacts providing an additional diffusion path (see e.g. ${ }^{3,9}$ ).

Indentation/truncation and overgrowth microstructures have been observed in wet quartz sands compacted at effective pressures of several tens to hundreds of $\mathrm{MPa}$ and temperatures up to $300-500{ }^{\circ} \mathrm{C}$, and these features have been interpreted as evidence for the operation of IPS ${ }^{4,11,19}$. Similar microstructures have been observed in (simulated) quartz and quartz-phyllosilicate fault gouges deformed in laboratory experiments settings ${ }^{20}$. However, because of the post-mortem nature of the observed microstructures (i.e. representing the end-product of deformation) and insufficient information on initial and final grain boundary structure, the intergranular dissolution mechanism, i.e. grain boundary diffusion in a thin film or island-channel structure, vs. marginal dissolution and/or contact crushing, remains difficult to identify and may involve several or all of the above. The two experiments reported in this paper were directed at shedding light on the mechanisms operating at stressed grain contacts during IPS in quartz. To accomplish this, we investigated changes in the morphology of contacts between quartz grains and polished, single crystal quartz "plates" and "blocks" (here termed inclusions) embedded within fluid-saturated ("wet") quartz sand samples compacted at hydrothermal conditions. So, only the plate and the general grain size/shape of the sand were known, not the initial contact geometry at grain-plate contact.

As explained below, in the two experiments, we used different quartz sand materials, different apparatus setups and different effective stresses. This makes comparison and unambiguous interpretation of the results difficult, but the experiments nonetheless produced interesting and rather surprising microstructures which (we hope) will stimulate further work where experimental variables will be systematically varied.

\section{Experimental method}

Sample preparation and compaction method-experiment QC13. Single crystal quartz inclusions. Quartz cylinders with a diameter of $1 \mathrm{~cm}$ and a length of $1.5-2 \mathrm{~cm}$ were cored from inclusion-free Brazilian quartz crystals in directions parallel to the crystallographic r-axis and m-axis (Supplementary Fig. 2). Cylindrical quartz discs with a thickness of 1.5-2 mm thickness were prepared by cutting perpendicular to the long axis of the cylinder. Half-cylinders and quarter-cylinders were prepared by cutting parallel to the long axis of the tube. The saw-cut surfaces were first manually ground using abrasive paper and then automatically polished for about $24 \mathrm{~h}$ on progressively finer abrasive paper (Emery 4/0) in the presence of a water-based SiC paste. This procedure resulted in plate- and block-like inclusions with a high-quality, virtually scratch-free, surface finish (Supplementary Fig. 3a). The dimensions of the quartz crystal inclusions used in the present tests and the crystallographic orientations of the polished surfaces are listed in Table 1 and the experimental conditions in Table 2.

Quartz sand. Quartz sand obtained from the Miocene "Bolderiaan" formation (Maasmechelen, Belgium) was used as indenter material. The sand was sieved into a grain size fraction of $125-150 \mu \mathrm{m}$, ultrasonically vibrated to remove adhering fines, washed with distilled water and then etched in a HF solution (0.5-1 N, dura- 


\begin{tabular}{|l|l|l|}
\hline Experiment & QC13 & QC14 \\
\hline Temperature $\left({ }^{\circ} \mathrm{C}\right)$ & 350 & 350 \\
\hline Maximum applied confining pressure, $\mathrm{Pc}(\mathrm{MPa})$ & 27.5 & 45.0 \\
\hline Maximum vapour pressure, Pf-max $(\mathrm{MPa})$ & 15.5 & 17.0 \\
\hline Maximum effective pressure, Pe-max $(\mathrm{MPa})^{1}$ & 15.0 & 28.0 \\
\hline Experiment duration $($ days $)$ & 62 & 61 \\
\hline Initial sample volume $\left(\mathrm{mm}^{3}\right)$ & 5937.6 & 124.5 \\
\hline Volume of polished crystal $(\mathrm{s})$ plus sand $\left(\mathrm{mm}^{3}\right)$ & 3207.5 & 82.8 \\
\hline Initial pore volume $\left(\mathrm{mm}^{3}\right)^{2}$ & 2730.1 & 41.7 \\
\hline Initial porosity $(\%)^{3}$ & 46.0 & 33.5 \\
\hline Initial pore fluid composition & 1000 ppm $\mathrm{SiO}_{2}($ aq $)$ & d.d. $\mathrm{H}_{2} \mathrm{O} \mathrm{SiO}_{2}(\mathrm{aq})$ \\
\hline Liquid volume added at $20^{\circ} \mathrm{C}\left(\mathrm{mm}^{3}\right)$ & All pores filled with brine & 10.5 \\
\hline
\end{tabular}

Table 2. Experimental conditions. ${ }^{1}$ Calculated from vapour pressure data ${ }^{21}$, assuming liquid plus vapour present in the capsule. Pressure of included air is assumed negligible. ${ }^{2}$ Inner volume of the capsule minus the volume of quartz. ${ }^{3} \mathrm{~A}$ lower porosity was achieved for QC14 by gently agitating the gold capsules during and for 5 min after filling with sand.

tion $\sim 20 \mathrm{~min}$ ) to remove possible surface damage ). After the HF treatment, the sand was successively rinsed with $\mathrm{NaOH}$ solution of decreasing strength $(0.5 \mathrm{~N}, 0.01 \mathrm{~N}$ and $0.001 \mathrm{~N})$, washed with de-ionized water, and then dried for 3 days at $45^{\circ} \mathrm{C}$. Most quartz grains were characterized by crystallographically controlled surface patterns of cusp-shaped asperities $(0.5-1 \mu \mathrm{m})$ and triangular, pyramidal and sickle-shaped etch pits $(0.1-0.5$, $\mu \mathrm{m}$, Supplementary Fig. 3b). Most grains were rounded or at least displayed rounded edges, probably due to the etching by HF preferentially dissolving sharp edges.

Sample assembly and compaction procedure. A single cylindrical quartz plate was included at the base of sand sample QC13, formed by depositing the crystal and sand into a 1-D piston-cylinder (oedometer) type compac-

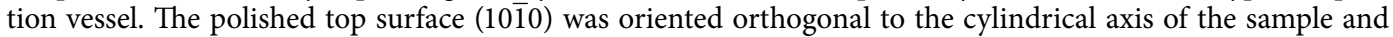
vessel, so that the applied (total) axial stress was transmitted to this quartz face via the overlying quartz grains (the matrix, see Supplementary Fig. 3c). Axial compaction was conducted using a piston-cylinder (oedometer) type compaction vessel under wet conditions (see definition below) at $350{ }^{\circ} \mathrm{C}$, for 62 days, under effective axial stresses stepped in three increments of 5 to $15 \mathrm{MPa}$. In such an oedometer test, the effective radial stress is not known, yet it can be safely assumed that some effective radial stress (i.e. support pressure) is exerted on the grains above and at the quartz crystal interface. The details of the vessel and of the experimental procedure are described by Schutjens ${ }^{22}$. The pore fluids were prepared by dissolving analytical grade sodium-metasilicate salt $\left(\mathrm{Na}_{2} \mathrm{SiO}_{3} \cdot 5 \mathrm{H}_{2} \mathrm{O}\right)$ at $20^{\circ} \mathrm{C}$ in double-distilled water to obtain a solution of $1000 \mathrm{ppm} \mathrm{SiO}{ }_{2}$, which is the equilibrium concentration with respect to quartz at the desired testing temperature and fluid pressure (calculated using data compiled by ${ }^{23}$ ). This was done to minimize dissolution of the quartz sand by any mechanism other than stressrelated solution transfer effects.

Sample preparation and compaction method-experiment QC14. Single crystal quartz inclusion. The preparation procedure of the quartz crystal faces in test QC14 was identical to that in QC13. In QC14, however, quarter-cylinders were used instead of cylindrical discs (see Supplementary Fig. 2). The polished quartz faces (referred to here as polished facets) were parallel to crystal planes (17 $\overline{6} 3)$ and ( $\overline{4} 314)$.

Quartz sand. In experiment QC14, quartz grains from the weakly consolidated St. Peter sandstone from the Ordovician (provenance USA) were used as indenters. A sieved fraction of 125-150 $\mu$ m was ultrasonically cleaned in tap water and dried for $2-3$ days at $45^{\circ} \mathrm{C}$. Most grains were well-rounded. The following surface morphologies were distinguished. Firstly, the largest part of the surface (60-70\%) was found to be characterized by a mosaic-pattern of tabular, relatively flat surfaces (width: $2-5 \mu \mathrm{m}$ ) separated by randomly oriented microchannels of about a micron in diameter (Supplemental Fig. 4a). The remainder of the surface of the quartz grains showed a crystallographically controlled pattern of cusp-shaped and serrated ridges with a relief of 1-3 $\mu \mathrm{m}$ (Supplemental Fig. 4b).

Sample assembly and compaction procedure. Sample QC14 was compacted hydrostatically in a closed system containing the quartz inclusion with two polished facets, quartz sand and water in liquid and vapour phase (Supplemental Fig. 4c). To achieve this, the quartz single crystal inclusion was placed in a gold capsule (outer diameter $6 \mathrm{~mm}$, wall thickness $0.2 \mathrm{~mm}$ ) and the quartz sand was funneled around the crystal. The capsule was agitated during and for some $5 \mathrm{~min}$ after filling with sand, in order to obtain a denser packing of the grains. The capsule was closed with a gold lid and welded along the contact between capsule and lid, leaving a small opening. After weighing the capsule (accuracy: $\pm 0.1 \mathrm{mg}$ ) the volume of air inside the capsule was calculated. Knowing the air volume and assuming a sand porosity under stress of about $25 \%$, a calculation was made of the volume of water required to maintain water vapour present next to liquid water at the testing temperature of $350{ }^{\circ} \mathrm{C}$. 

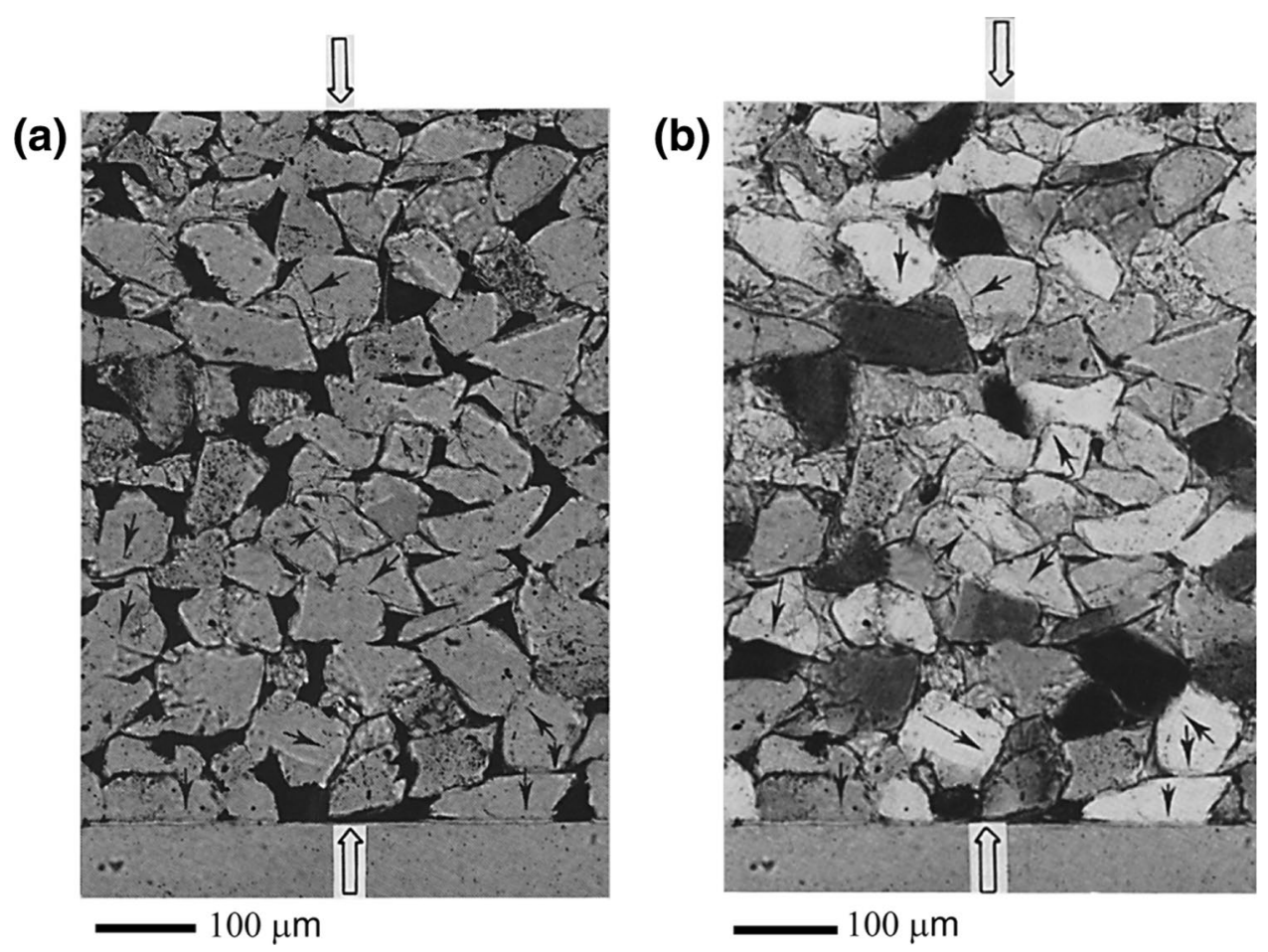

Figure 1. Overview photomicrographs of quartz sand compacted wet at $350{ }^{\circ} \mathrm{C}$ in test QC13. (a) Plane polarized light, with pores colored black. (b) Crossed polars. Both photomicrographs show the same part of a thin section cut parallel to the cylindrical axis of the sample (i.e. parallel to the direction of the applied effective stress, indicated by the open arrows). Notice the grain contact truncation and grain indentation microstructures (thin arrows). Just visible at the bottom is the polished cylindrical quartz crystal. Note conspicuous grain contact truncation of quartz grains from the matrix against this crystal.

The presence of both liquid and vapour water in a closed hydrothermal system allows estimation of the pore fluid pressure (= the vapour pressure of water at the testing temperature), which is then more or less independent of the amount of quartz sand compaction. Based on the standard tables of the liquid-vapour equilibrium of water at elevated temperature ${ }^{21}, 10.5 \mathrm{ml}$ of water was added to the sample using a syringe inserted through the opening at the top of the capsule. The opening was closed by pinching the lid flap against the inner wall of the capsule, the capsule was weighed to determine the amount of water added and then weld-sealed. Evaporation of the water due to welding was minimized by mounting the capsule on top of a copper heat-sink immersed in liquid nitrogen. The welded capsule was tested for leakage by immersion in oil at a temperature of $120^{\circ} \mathrm{C}$. The dimensions were measured with a caliper. The filled capsule was placed in an externally heated Tuttle pressure vessel and compacted hydrostatically using Argon gas as a pressure medium. The confining pressure $\left(\mathrm{P}_{c}\right)$ was applied by manually opening and closing the link valve between the pressure vessel and an independently pressurized Argon reservoir-and was measured with a $50 \mathrm{MPa}$ full scale pressure transducer. Every 6 to $12 \mathrm{~h}, \mathrm{P}_{\mathrm{c}}$ was increased in steps of about $3 \mathrm{MPa}$ until a final value of $45 \mathrm{MPa}$ was reached. After each $\mathrm{P}_{\mathrm{c}}$-increment, the temperature of the vessel was increased by 20 to $30^{\circ} \mathrm{C}$. The pore fluid pressure at a given temperature was taken as the vapour pressure at that temperature, assuming liquid water to be present in the capsule at every stage during the experiment. Based on the liquid-vapour data of water at elevated temperature ${ }^{21}$, the confining pressure increments were chosen such that the corresponding increase in confining pressure was somewhat greater than the increase in pore fluid pressure. In this way, the effective confining pressure was gradually increased from zero $\mathrm{MPa}$ at $20^{\circ} \mathrm{C}$ to about $28 \mathrm{MPa}$ at $350^{\circ} \mathrm{C}$ (i.e. with a confining pressure of $45 \mathrm{MPa}$ and the vapour (pore) pressure of about $17 \mathrm{MPa}$ ). For a period of 61 days, the capsule was maintained at a constant $\mathrm{P}_{\mathrm{c}}$ of $45 \mathrm{MPa}$, a constant (inferred) pore pressure of $17 \mathrm{MPa}$ and a constant temperature of $350{ }^{\circ} \mathrm{C}$. After termination of the experiment, the quartz single crystals were taken from the vessel (QC13) and capsule (QCI4) with a rubber-coated pair of tweezers, washed in de-ionized water, dried and prepared for microstructural analysis.

\section{Experimental results}

Results of experiment QC13. Aggregate microstructure. Figure 1a,b shows optical micrographs of the compacted sample of experiment QC13 (the oedometer test). The polished quartz single crystal is visible at the bottom of the photographs. Abundant truncated and concavo-convex grain-to-grain contacts were observed in the matrix of Bolderiaan quartz grains located above the polished quartz crystal (Fig. 2a, i.e. at contacts between individual quartz grains), as well as clusters of euhedral quartz crystals in the pores (Fig. 2b). Microstructural evidence was found for truncation of matrix quartz grains against the face of the polished quartz crystal located 

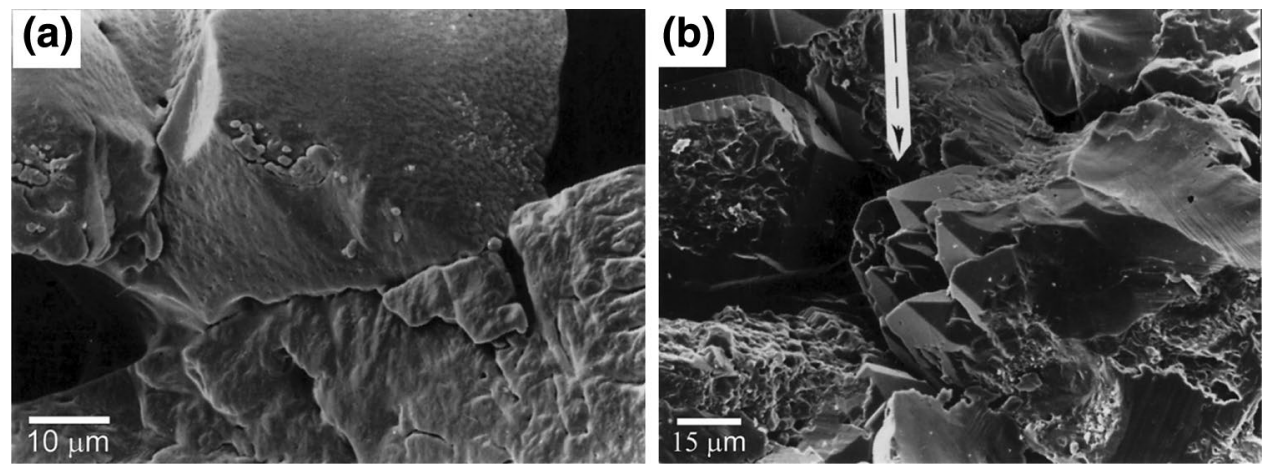

Figure 2. (a) Characteristic grain contact truncation microstructure in wet-compacted sample QC13 $\left(\mathrm{T}=350^{\circ} \mathrm{C}\right)$. Note that only one of the two grains in contact appears to have undergone dissolution. This feature is observed at nearly all the truncated/indented grains. Note also the absence of marginal dissolution features.

(b) Euhedral quartz crystals in the pores of the wet-compacted sample QC13.

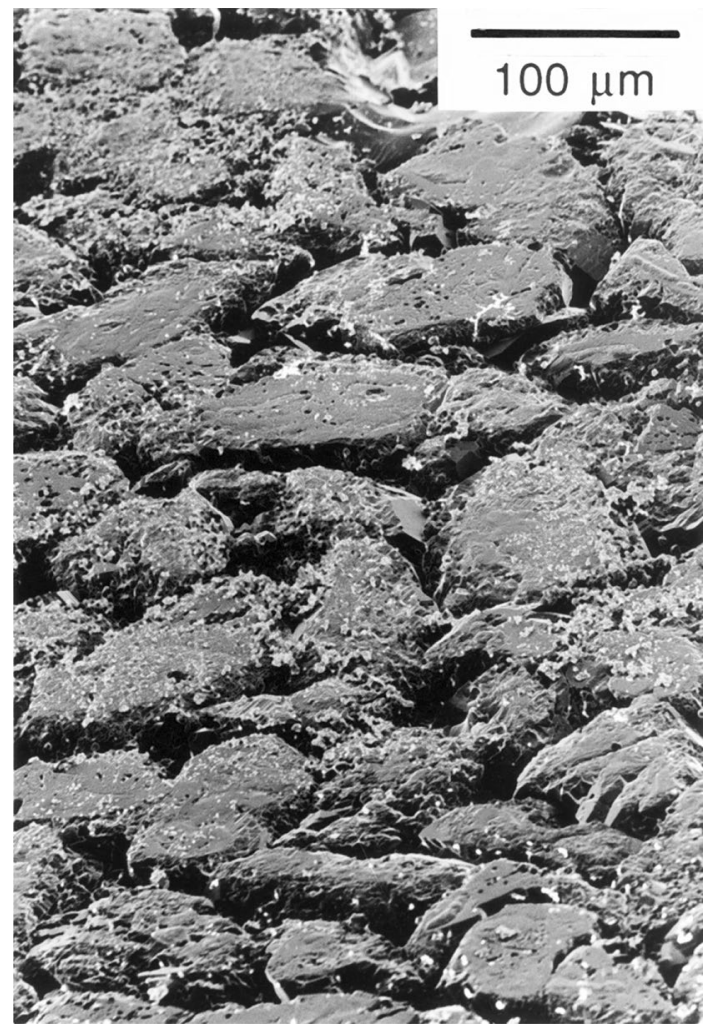

Figure 3. SEM micrograph showing top surface of the truncated quartz crystals after removal of the polished quartz plate. Note flat top surface of the grains.

at the base of the sample (Fig. 3) but no pitting of quartz grains into the crystal was observed with the optical microscope.

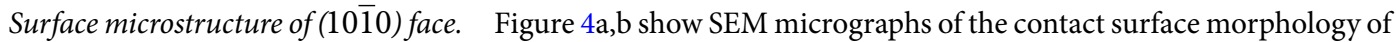
quartz grains which were pressed against the polished quartz crystal face. Note the conspicuous flat top surface (estimated roughness $<500 \mathrm{~nm}$ ), confirming the impression gathered from optical microscopy of widespread truncation of the quartz grains against the polished $(10 \overline{1} 0)$ face. The flat top faces display a wide variety of inclusions, varying in shape from triangular and inverse-pyramidal (Fig. 4a) to sub-rounded (Fig. 4b), and ranging in size from several hundred nanometers to about 3-4 $\mu \mathrm{m}$. The intervening regions between the inclusions appear to be flat within SEM resolution, which implies that the surface relief (if any) in these regions is smaller than about $10 \mathrm{~nm}$. SEM observations confirmed that pits into the polished crystal surface are virtually absent. The few pits that were seen with the SEM are oval-shaped and have a long dimension in the range 3 to $10 \mu \mathrm{m}$ 

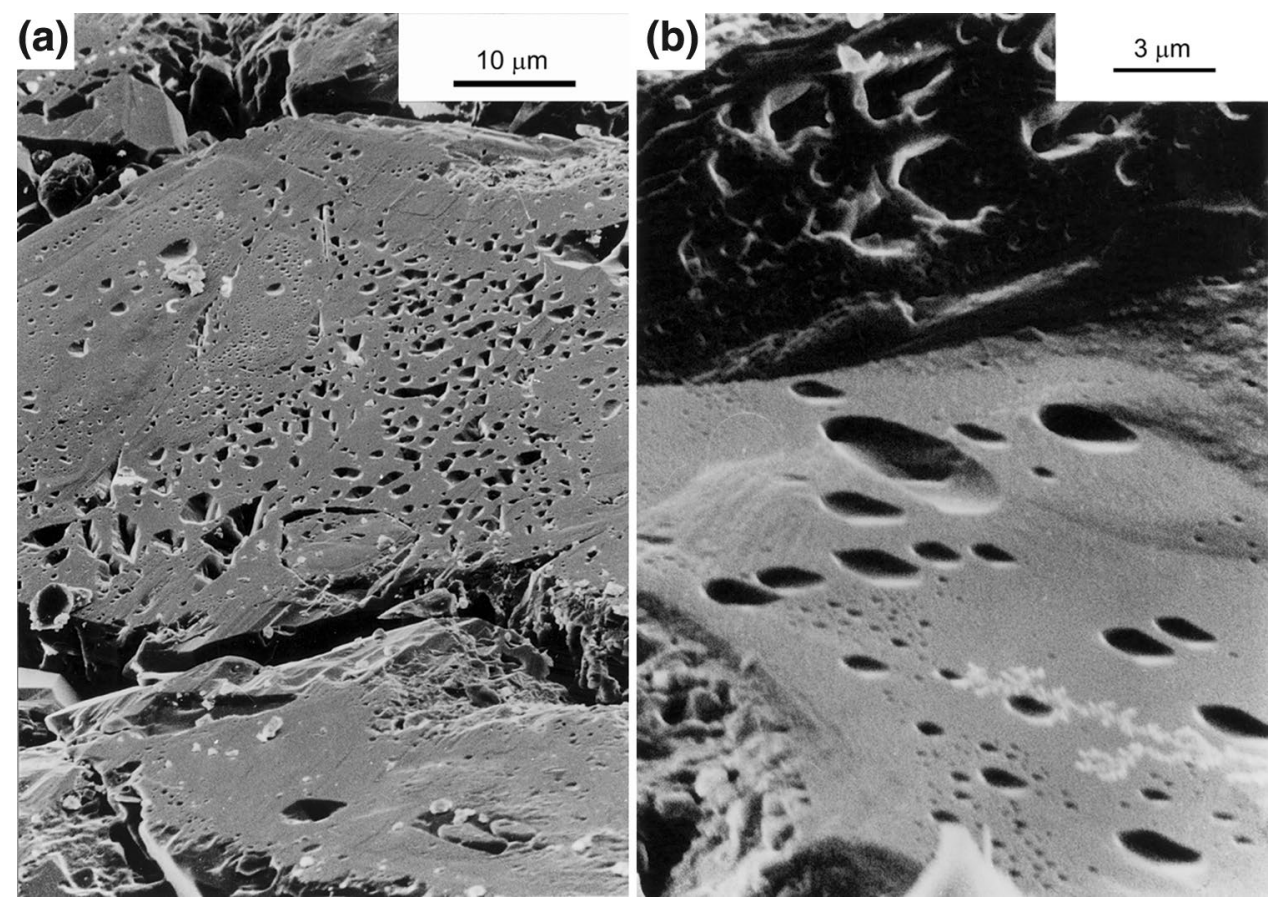

Figure 4. (a,b) SEM micrographs of truncation interfaces of the grains which were in contact with the quartz plate. Note the inclusion morphologies and the flat intervening regions between the apparently isolated inclusions.

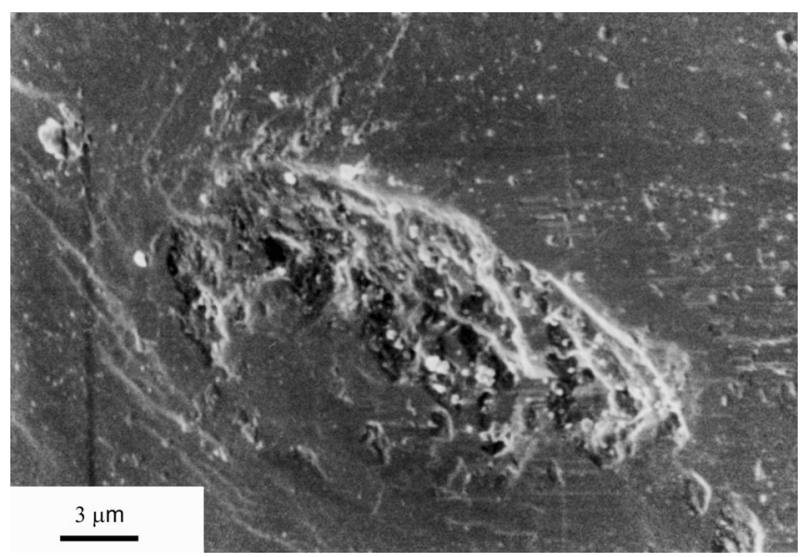

Figure 5. Indentation in the polished crystal face used in test QC13. Only a few of these indentations were observed; most matrix crystals which were in contact with the polished quartz crystal face were truncated without indenting the polished crystal face. Note fine grained debris in and around the pit (inferred to have formed during compaction).

(i.e. relatively small compared to the size of the pits developed on face (4314) in experiment QC14, see below). The boundary between pits and the polished surface is indistinct, and numerous submicron-size particles are visible at and around these pits (Fig. 5, white-colored in view). These must have formed during experimental compaction or during cooling, since the starting surface of the quartz crystals was free of adhering particles. No overgrowths were seen on the quartz plate, but limited overgrowths features did develop on quartz grains in the sample, see Fig. $2 b$.

Results of experiment QC14. The extracted gold capsule was crumpled around the sample and clear imprints of the quartz grains had developed on the inner wall of the capsule. SEM micrographs of the polished quartz faces included in this test are shown in Fig. 6. Abundant sub-elliptical and occasionally sub-circular pits formed on the polished surface with orientation (4314). Their long dimension lays in the range 30 to 60 microns and is apparently randomly oriented. In most pits, the depth of the pits below the polished surface was found to 

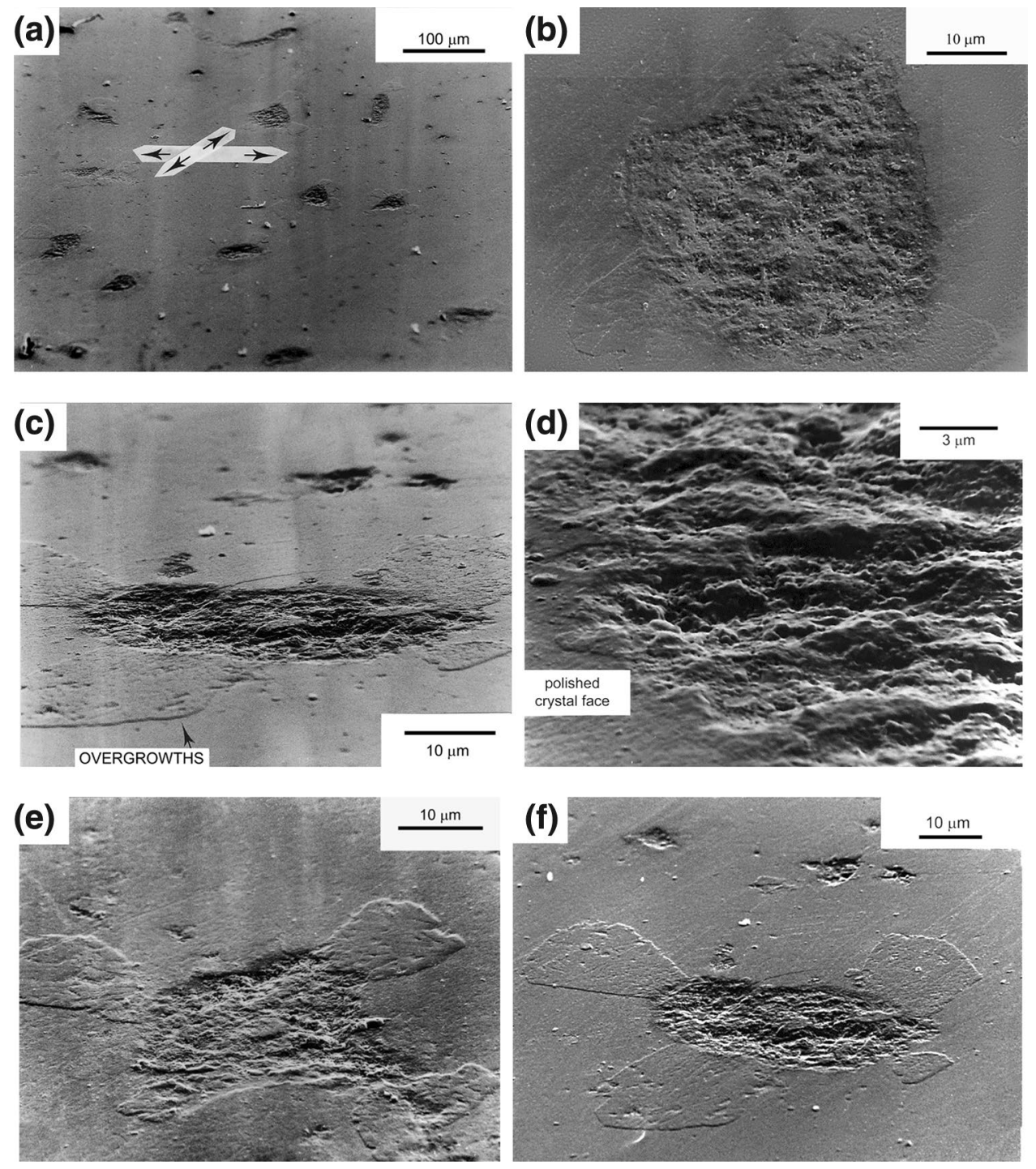

Figure 6. Micrographs of "pits" surrounded by clover-shaped precipitation microstructures, developed on the polished quartz crystal in experiment QC14. (a) SEM micrograph of pits on crystal face ( $\overline{4} 314)$, birds-eye view. (b) Micrograph of pit taken perpendicular to a pit surface. crystal face ( $\overline{4} 314)$. (c) Birds-eye view of pit on face (4314). (d) Micrograph showing the typical rough surface structure of the pit and the sharp transition between the "rough" pit and the "smooth" polished crystal face. (e,f) Typical "4-leaf clover" geometry of overgrowth developed around pits. Note the different size of the "clovers". Also note the shape preferred orientation of the overgrowth features in Fig. 6a (indicated by arrows).

gradually increase towards the center of the pit to estimated values of 3 to $10 \mu \mathrm{m}$ ("bowl" shaped pits). In other pits, the depth below the surface is more or less constant over the entire surface area. Figure $6 \mathrm{~b}$ shows a typical pit morphology viewed perpendicular to the polished quartz-crystal face. Views at low angles to both types of pits reveal a relatively homogeneous surface morphology characterized by a micro-relief of blunted knobs, ridges and furrows, occasionally cross-cut by zones showing cuspate ("sharp") surface features (Fig. 6c). From SEM observations, we estimate that the relief ranges from several hundred nanometers up to a few micrometers, with an estimated average of $1 \mu \mathrm{m}$. Note the distinct transition from the "smooth" polished surface to the "rough" surface of the pit (Fig. 6d).

The indenter grains corresponding to the pits were not recovered, and so the actual amount of mass removal associated with formation of a given pit is unknown. On the same polished crystal face $(\overline{4} 314)$ many pits were seen to be bordered by tabular elevations with a typical lobate shape (Fig. 6c, see arrow at base). Because the starting surface was perfectly flat, material is inferred to have precipitated during hydrothermal compaction and will therefore be referred to here as "overgrowth". Though hard to determine precisely, the overgrowth features have an elevation of about $1 \mu \mathrm{m}$ above the polished surface (this is our coarse estimate from inspection of the photographs), cover surface areas in the range of $200-500 \mu \mathrm{m}^{2}$ and appear to be in crystallographic continuity with the substrate crystal (since no euhedral overgrowths were seen). Pits show in general four overgrowths, 
occasionally three, but rarely more than four. One of the overgrowths is often considerably smaller than the others (as in Fig. 6c,e,f). The longest dimension of the individual overgrowths (measured perpendicular to the rim of the pit) is nearly always oriented at an angle of $90^{\circ}$ to that of the neighboring overgrowth, giving rise to a characteristic "4-leaf clover" geometry, with the pit in the center. The orientation of the clover-leaf overgrowth geometry on the polished face is constant with respect to an external reference frame (indicated by arrows in Fig. 6a). The size of the pits seems to be in qualitative agreement with the size of the bordering overgrowths: the bigger the pit, the bigger the overgrowths around it. No attempt was made for quantitative petrography to gather data to study and map the size and distribution patterns of the indentation-overgrowth microstructures.

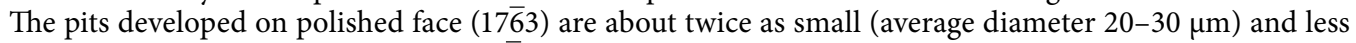
deep $(5 \mu \mathrm{m})$ than those developed on the $(\overline{4} 314)$ face, as descbed above (see Supplemental Fig. 2$)$. The surface relief of the pits on $(17 \overline{6} 3)$ is also less pronounced than on $(\overline{4} 314)$ but is of similar morphology. Limited evidence was also found for "clover-leaf' overgrowths around these pits, again with the longest dimension of the individual overgrowths (measured perpendicular to the rim of the pit) being oriented at an angle of $90^{\circ}$ to that of the neighboring lobate overgrowth.

\section{Interpretation}

Deformation mechanism. The following observations are of interest to identify the mechanisms active during hydrothermal compaction in tests QC13 and QC14:

1) The pits in the polished quartz surfaces form at the locations where the grains from the matrix are in contact with the quartz crystal plates, and are thus not due to dissolution variation caused by e.g. along-surface variation in dislocation density due to polishing or impurities in the quartz crystal.

2) The shape of most pits is rounded to sub-rounded (see Fig. 6b) with their depth gradually increasing towards its pit-center. The pit-surface rugosity is not smooth and probably reflects the morphology of the indenting quartz grains. This indicates that material has been removed by dissolution rather than pushed aside after progressive brittle deformation. In that case, probably a more irregular pit surface with sharp ledges and fractured parts would have formed.

3) Because no evidence was found for pit development by fracturing and because plastic deformation of quartz can be ruled out at these relatively low PT conditions ${ }^{24}$, it is inferred that the pits seen in QC13 and QC14 were formed by stress and/or strain-induced solution transfer (i.e. IPS) from the contact points between polished crystal facets and quartz grains. We think that the truncation microstructures observed in the axial compaction test QC13 are also indicative of IPS.

4) QC13 and QC14 were conducted at similar temperature $\left(350{ }^{\circ} \mathrm{C}\right)$, similar applied effective pressure (a few tens of $\mathrm{MPa}$ ) and similar duration (two months). Despite the difference stress application (axial loading in oedometer vs hydrostatic loading) and different surface morphology of the quartz sand, IPS was observed in both tests. Mechanism-based grain-scale models for pressure solution predict IPS to occur at these conditions ${ }^{4,15}$.

5) The morphology of the pits seen in test QC14 suggests that they formed by uniform indentation of the St. Peter quartz grains into the polished faces, and not by some mechanism of free-face dissolution around the small ("undercut") points of contact. In the latter mechanism, a tabular "neck"-shaped contact would be expected, surrounded by regions with a flat or crystallographically-controlled surface morphology (as proposed by ${ }^{18}$. This was not seen in our samples.

6) The precipitation on the polished quartz faces occurs only where the pits are (see Fig. 6e,f), providing additional evidence that the pits formed by dissolution.

7) The "clover-leaf" geometrical configuration around the pits and their uniform orientation on the quartz crystal face (see Fig. 6b) suggests control by the internal structure of the quartz crystal on their formation. Quartz has a trigonal symmetry and is mechanically anisotropic, with the a-axis being $~ 50 \%$ more compressible than c-axis ${ }^{25}$. Differences in the dissolution rates of different crystal faces of quartz have been implied from both field work (e.g. ${ }^{8}$, experimental studies (e.g. ${ }^{26}$ ) and theoretical analysis (e.g. $\left.{ }^{27}\right)$. The clover-leaf overgrowth pattern with orthogonal directions could also be caused by crystallographically controlled strain energy variation across the quartz-crystal face, i.e. defining regions of relatively low and high stress ("stress shadows") or regions of relatively high/low dislocation density that act as locations for preferential precipitation ("step propagation from dislocation defect" ${ }^{\text {"28,29) }}$ ).

8) The observation of truncation against the (1010) quartz crystal face in test QC13 and of indentation in the $(17 \overline{6} 3)$ and $(\overline{4} 314)$ faces in test QC14 points to control of crystallographic orientation on IPS.

9) The pits that developed in test QC14 on polished face (1763) are about twice as small (average diameter 20-30 $\mu \mathrm{m})$ and less deep $(5 \mu \mathrm{m})$ than those developed on the ( $\overline{4} 314)$ face, as described above. This also suggests control by the quartz crystal lattice on the rate of IPS.

10) The sub-rounded to crystallographically controlled shape of the inclusions at the truncated quartz grains seen in test QC13 (Fig. 4a,b) resemble grain boundary structures from natural sandstones where IPS occurred ( ${ }^{3}$, their Fig. 4) and suggest the operation of surface-energy-driven solution and precipitation inside the grain contact interface. Inspection of the truncated contacts in test QC13 (Fig. 4b) suggests that the surface roughness is below $500 \mathrm{~nm}$. This seems to favor the thin-film hypothesis although some "dynamic" island-channel microstructure inside the quartz-quartz contact cannot be ruled out.

Summarizing, it is inferred that the indentations in tests QC13 and QC14 and truncations in test QC13 formed by a process of grain boundary diffusional mass transfer, with the effective grain boundary width 

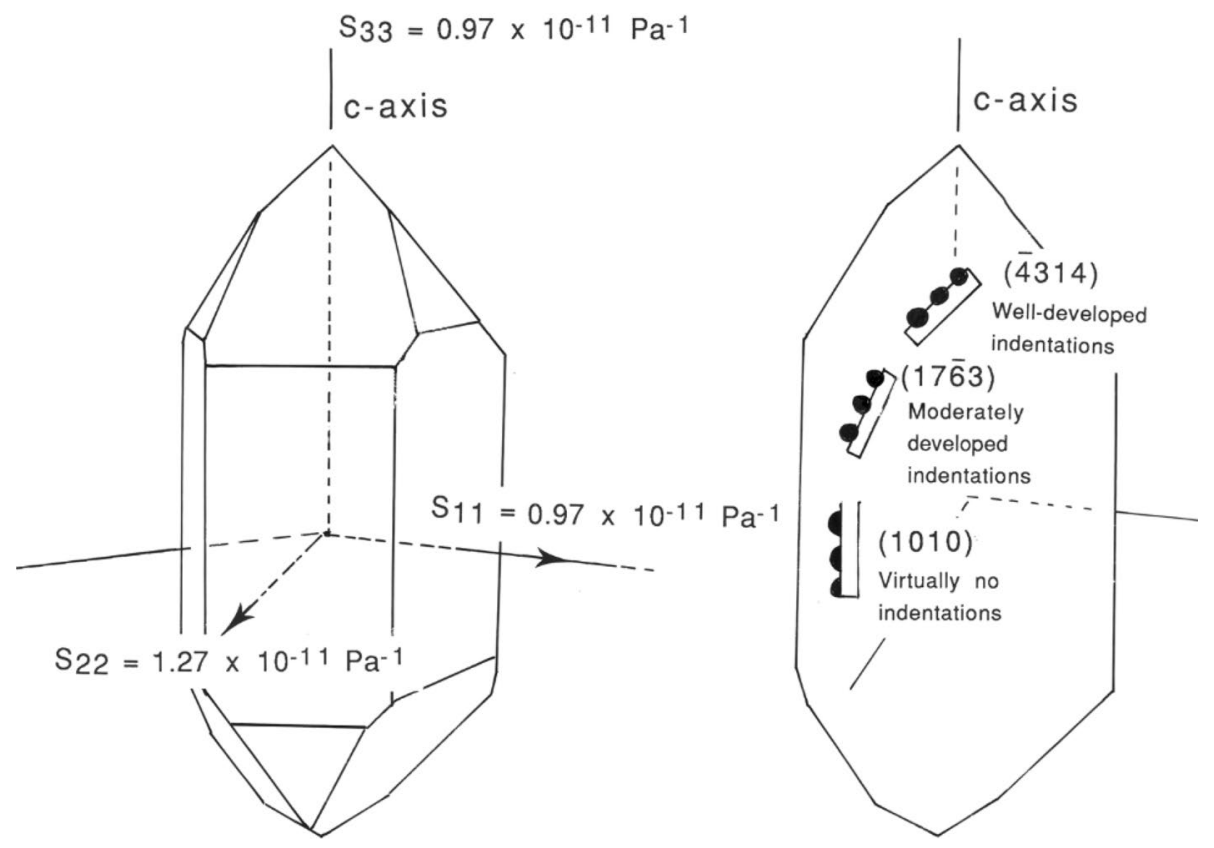

Figure 7. Schematic diagrams illustrating the variation in compliance in quartz with crystallographic orientation (a) and the degree of pit development of the quartz faces (b), oriented with respect to the c-axis of the Brazilian quartz crystal.

governed by the surface structure of the indenting quartz grains, with $1 \mu \mathrm{m}$ as upper limit and less than $500 \mathrm{~nm}$ at the "flat" regions like the ones shown in Fig. 4a.

Comparison to experiments of Renton and Gratier. In test QC14, evidence for IPS at the quartzcrystal facets was provided by the presence of overgrowths close to the indentations. Stress trajectories on an indenter-loaded quartz surface likely take the shape of clover-leafs, at least for near-spherical indenters like the Bolderiaan and St. Peter quartz grains, with modification due to the anisotropic elastic properties of the quartz crystal. Assuming that the clover leafs are indeed elevations and not depressions and assuming that the concentration of dissolved silica is radially symmetric, the areas covered by the clover leafs must be areas of low strain energy density, presumably controlled by the anisotropic elastic strain field around the indenter.

Similar indentation features were observed by Renton et al. ${ }^{19}$ in hydrostatic compaction experiments using polished faces of quartz crystals surrounded by small (inert) zircon grains in the presence of a fluid phase. In their experiments, elliptical to sub-rounded pits were produced on the polished quartz faces, with the extent of pit formation increasing with $\mathrm{pH}$ and salinity of the pore fluid. The surface morphology of their pits was also rough, but instead of a random distribution of protuberances, ridges and furrows (as in the present experiments) surface relief was characterized by an annular pattern composed of alternating ridges and valleys and by radial solution grooves. Renton and coworkers also observed overgrowth features at the rims of the pits,-but mention no particular shape of these overgrowths. The fact that the observed overgrowths formed at the rims of the indentations led Renton and coworkers to conclude that the solute did not move far from the site of dissolution. Our observations, including a qualitative correlation between pit and overgrowth volume, support this conclusion.

Steel indenter experiments in quartz crystal surfaces by Gratier and co-workers demonstrated the occurrence of stress-induced axially symmetric cracks below the surface of the indenter and extending out into the crystal face $^{16}$. In their experiments, the axially symmetric cracks acted as fluid channels leading to free face dissolution. We did not observe any evidence for such micro-cracking at the quartz surfaces, but microcracks may have been present inside the quartz crystal (this could be investigated with thin section analysis, which we did not do) or microcracks might have been present during the earlier stage of the experiments. On the other hand, perhaps microcracks did not form in our experiments because the confining pressure was much lower than the normal stress applied in the Gratier et al. indenter study ( $28 \mathrm{MPa}$ in present test QC14 vs. up to $300 \mathrm{MPa}$ in the Gratier et al. experiments).

On the morphological differences of contacts between quartz grain and polished quartz crustal. A substantial variation in indentation vs. truncation morphology was seen in tests QC13 and QC14. In test QC13 truncations were well developed, whereas in test QC14 indentation "pits" were apparently predominant (note that truncations at the indenting quartz grains cannot be ruled out). In addition, well-developed indentations developed in a quartz face $(\overline{4} 314)$ with normal at a small angle to the c-axis, whereas much smaller indentations were seen on the quartz face $(17 \overline{6} 3)$ with normal at a higher angle to the c-axis (Fig. 7 ). If this apparent orientation-dependence of the supposed extent of IPS is a real orientation effect (as opposed to being 
related to the different shapes of the grains in the two sands used, or to differences in the chemical composition of the quartz sands, or to the hydrostatic versus $1 \mathrm{D}$ compaction set-ups used), it may be due to an influence of the crystal orientation on the kinetics of dissolution at the single crystal surface, or possibly even the driving force for pressure solution through a dependence of solid chemical potential on contact shear stress as well as normal stress ${ }^{30,31}$. The deduction of an effect of kinetics is supported by literature suggesting that the dissolution reaction kinetics of quartz in aqueous solutions may vary with crystallographic orientation (e.g. ${ }^{32-34}$. Kennedy ${ }^{35}$ found that quartz cut with poles parallel to the c-axis (i.e. basal planes) reach equilibrium with water a factor 2 to 4 faster than quartz plates with poles along or close to the c-axis (i.e. rhomb or prism faces). Hicks et al. ${ }^{7}$ concluded from a petrographic study on IPS in quartz-rich sandstone that, given a concave-convex contact between two quartz grains, the c-axis of the concave grain tends to lie at a lower angle to the pole of the contact plane than does that of the convex grain (Supplementary Fig. 5). Bons and Den Brok ${ }^{27}$ modeled the development of Crystal Preferred Orientations (CPOs) for the case of reaction-controlled pressure solution,-and only a twofold contrast in dissolution kinetics was needed to obtain CPOs similar to those observed in natural quartz-rich rocks $^{36,37}$.

The above observations are in qualitative agreement with the present variation in inferred extent of IPS with crystallographic orientation of the polished quartz faces. However, it must be kept in mind that the variation in IPS microstructures may equally well (or partly) reflect the difference in experimental configurations, materials and testing conditions. More systematic experiments are needed to investigate the influence of experimental conditions on the IPS mechanism in the quartz-water system in greater detail and to assess the magnitude, systematics and mechanistic origin of orientation effects on IPS rates.

\section{Conclusions and recommendations}

Polished quartz crystals embedded in wet quartz sand and axially or hydrostatically compacted in the presence of a fluid phase at a temperature of $350^{\circ} \mathrm{C}$ and effective pressures of $15 \mathrm{MPa}$ (axial loading) and $28 \mathrm{MPa}$ (isotropic loading) show convincing evidence for IPS. This confirms predictions from mechanism-based models. Axial compaction gave truncation of quartz grains against the quartz plates. Hydrostatic compaction led to the development of indentations in the polished crystal faces and to the formation of overgrowths on the polished crystal faces. Truncations at indenting quartz grains may also have developed but to what extent is unknown. The morphology of the indentation pits and the truncations suggests the formation of these by grain boundary diffusional IPS rather than by marginal dissolution. The surface morphology of the indentations is characterized by protuberances, ridges and furrows with relief ranging from several hundred nanometers to a few microns. The surface morphology at the truncated contacts consists of inclusions of sub-rounded to crystallographically controlled shape separated by smooth intervening regions. The experimental observations agree with experimental and petrographic data suggesting crystallographic control of (stress-induced) dissolution rate, with relatively rapid dissolution kinetics at quartz face $(\overline{4} 314)$ and relatively slow dissolution kinetics at quartz face $(17 \overline{6} 3)$.

We report here on only two experiments, yet we hope that the microstructures and interpretation of the deformation mechanisms will stimulate further work. Our experiments are quite simple, i.e. they do not require a high-temperature triaxial deformation apparatus (a pressure cell that can be heated will do), - and the samples can be readily and cheaply made. This may facilitate further experimental research, e.g. with different hydrothermal quartz-water mixtures to apply different effective confining pressures on several gold-capsuled samples loaded in the same experiment. The crystallographic orientation of the polished quartz face in contact with the quartz grains in the matrix can then be varied in a systematic manner to study the effect of CPO on IPS. If such experiments reveal similar IPS-microstructures as the ones reported here, quantitative interpretation of the volume removed by indentation and volume deposited by precipitation should be attempted using e.g. image analysis techniques from digital-rock applications or 3D-imaging using multi-side illumination techniques. The impact of quartz-grain surface morphology on IPS can be investigated by using samples of different natural quartz sands with different grain surface rugosity than Bolderiaan or St. Peter. Advanced etching or grinding techniques can be applied to either flatten or enhance asperities on the quartz grain surface, to investigate how it affects the morphology of grain boundaries in truncation and indentation microstructures produced by IPS. New experiments should also investigate whether roughness/furrows in the floor/faces of the pits/contacts (as in experiment QC14) are associated with cracks penetrating into the quartz crystal, ref. work by Renton et al. ${ }^{19}$ and Gratier et al. ${ }^{16}$.

In order to extrapolate experimental results to natural conditions, the full formulation of the serial processes of dissolution, diffusion and precipitation must be used to account for possible fluctuations in the rates of either of these processes. Clearly, to improve the understanding of the kinetics of the mechanisms operating during IPS in natural wet quartz-rich rocks, more detailed experiments are needed. Further insight in the potential importance of variability in dissolution, precipitation and diffusion rates for different crystal faces can be obtained from experimental and microstructural data combined with mechanism-based models in which the thermodynamics and kinetics of the pressure-solution process in water-saturated quartz sands is taken into account. 
Received: 2 May 2021; Accepted: 5 July 2021

Published online: 21 July 2021

\section{References}

1. Gratier, J., Dysthe, D. K. \& Renard, F. The role of pressure solution creep in the ductility of the Earth's upper crust. Adv. Geophys. 54, 47-179. https://doi.org/10.1016/B978-0-12-380940-7.00002-0.2 (2013).

2. Lehner, F. K. A model for intergranular pressure solution in open systems. Tectonophysics 245, 153-180 (1995).

3. Renard, F., Brosse, E. \& Gratier, J. P. The different processes involved in the mechanism of pressure solution in quartz-rich rocks and their interactions. International Association Sedimentologists Special Publication 29, 67-78 (2000).

4. Van Noort, R. V., Spiers, C. J. \& Pennock, G. Compaction of granular quartz under hydrothermal conditions: Controlling mechanisms and grain boundary processes. J. Geophys. Res. https://doi.org/10.1029/2008JB005815 (2008).

5. Bourne, S., Crouch, S. \& Smith, M. A risk-based framework for measurement, monitoring and verification of the Quest CCS Project, Alberta, Canada. Int. J. Greenhouse Gas Control 26, 109-126. https://doi.org/10.1016/j.ijggc.2014.04.026 (2014).

6. Poursoltani, M. R. \& Gibling, M. R. Composition, porosity, and reservoir potential of the Middle Jurassic Kashafrud Formation, northeast Iran. Mar. Pet. Geol. 28, 1094-1110. https://doi.org/10.1016/j.marpetgeo.2010.11.004 (2011).

7. Hicks, B. D., Applin, K. R. \& Houseknecht, D. W. Crystallographic influences on intergranular pressure solution in a quartzose sandstone. J. Sediment. Petrol. 56, 784-787 (1986).

8. Becker, A. Quartz pressure solution: influence of crystallographic orientation. J. Struct. Geol. 17(10), 1395-1405 (1995)

9. Renard, F., Ortoleva, P. \& Gratier, J.-P. Pressure solution in sandstones: influence of clays and dependence on temperature and stress. Tectonophysics 280, 257-266 (1997).

10. Rutter, E. J. \& Wanten, P. J. Experimental study of the compaction of phyllosilicate-bearing sand at elevated temperature and with controlled pore water pressure. J. Sediment. Res. https://doi.org/10.1306/2DC40902-0E47-11D7-8643000102C1865D (2000).

11. Giger, S. B., Tenthorey, E., Cox, S. F. \& Fitz Gerald, J. D. Permeability evolution in quartz fault gouges under hydrothermal conditions. J. Geophys. Res. 112, B07202. https://doi.org/10.1029/2006JB004828 (2007).

12. Giger, S. B., Cox, S. F. \& Tenthorey, E. (2008) Slip localization and fault weakening as a consequence of fault gouge strengthening - Insights from laboratory experiments. Earth Planet. Sci. Lett. 276(1-2), 73-84. https://doi.org/10.1016/j.epsl.2008.09.004 (2008).

13. Chen, J. \& Spiers, C. J. Rate and state frictional and healing behavior of carbonate fault gouge explained using microphysical model. J. Geophys. Res. Earth 121, 8642-8665. https://doi.org/10.1002/2016JB013470 (2016).

14. Spiers, C.J., Schutjens, P.M.T.M., Brzesowsky, R.H., Peach, C.J. Liezenberg and J.L. \& Zwart, H.J. (1990) Experimental determination of constitutive parameters governing creep of rocksalt by pressure solution. In: Knipe, R. ¿ Rutter, E.H. (eds) Deformation mechanisms, Rheology and Tectonics. Geological Society of London Special Publications 54, 215-227.

15. Gundersen, E., Dysthe, D. K., Renard, F., Bjørlykke, K. \& Jamtveit, B. Numerical modelling of pressure solution in sandstone, rate-limiting processes and the effect of clays. In Deformation Mechanisms, Rheology and Tectonics Vol. 200 (eds De Meer, S. et al.) 41-60 (Geological Society of London, 2002).

16. Gratier, J.-P., Guiguet, R., Renard, F., Jenatton, L. \& Bernard, D. A pressure solution creep law for quartz from indentation experiments. J. Geophys. Res. 114(B3), 1-16. https://doi.org/10.1029/2008JB005652 (2009).

17. Pluymakers, A. \& Spiers, C. J. Compaction creep of simulated anhydrite fault gouge by pressure solution: Theory v. experiments and implications for fault sealing. Geol. Soc. Lond. Spec. Publ. 409, 1. https://doi.org/10.1144/SP409.6 (2014).

18. Tada, R. \& Siever, R. Pressure solution during diagenesis. Ann. Rev. Earth Planet. Sci. Lett. 17, 89-118 (1989).

19. Renton, J. J., Heald, M. T. \& Cecil, C. B. Experimental investigation of pressure solution of quartz. J. Sediment. Petrol. 39, 1107-1117 (1969).

20. Niemeijer, A. R. Velocity-dependent slip weakening by the combined operation of pressure solution and foliation development. Nat. Sci. Rep. 8, 4724. https://doi.org/10.1038/s41598-018-22889-3 (2018).

21. Fisher, J. R. The volumetric properties of $\mathrm{H} 2 \mathrm{O}$ - a graphical portrayal. J. Res. U.S. Geol. Surv. 4, 189-193 (1976).

22. Schutjens, P. M. T. M. Experimental compaction of quartz sand at low effective stress and temperature conditions. J. Geol. Soc. London 148, 527-539. https://doi.org/10.1144/gsjgs.148.3.0527 (1991).

23. Walther, J. V. \& Helgeson, H. C. Calculation of the thermodynamic properties of aqueous silica and the solubility of quartz and its polymorphs at high pressures and temperatures. Am. J. Sci. 277, 1315-1351 (1977).

24. Paterson, M. S. The interaction of water with quartz and its influence in dislocation flow-An overview. In Rheology of Solids and of the Earth (eds Karato, S. I. \& Toriumi, M.) 107-142 (Oxford University Press, 1989).

25. Angel, R. J., Allan, D. R., Miletich, R. \& Finger, L. W. The use of quartz as an internal pressure standard in high-pressure crystallography. J. Appl. Crystallogr. 30, 461-466. https://doi.org/10.1107/S0021889897000861 (1997).

26. Den Brok, B. The effect of crystallographic orientation on pressure solution in quartzite. J. Struct. Geol. 18(6), 859-860. https:// doi.org/10.1016/S0191-8141(96)80018-6 (1996).

27. Chernov, A. A. Modern crystallography III. In Springer Series in Solid-State Sciences, Vol. 36 (eds Cardona, M. et al.) 48-158 (Springer, 1984).

28. Bons, P. D. \& Brok, B. D. Crystallographic preferred orientation development by dissolution - precipitation creep. J. Struct. Geol. 22, 1713-1722 (2000).

29. Dove, P. M., Han, N. \& De Yoreo, J. J. Mechanisms of classical crystal growth theory explain quartz and silicate dissolution behavior. Proc. Natl. Acad. Sci. U.S.A. 102(43), 15357-15362. https://doi.org/10.1073/pnas.0507777102 (2005).

30. Lehner, F. K. \& Bataille, J. Nonequilibrium thermodynamics of pressure solution. Pure Appl. Geophys. 122, 53-85. https://doi.org/ 10.1007/BF00879649 (1984).

31. Shimizu, I. Kinetics of pressure solution creep in quartz: Theoretical considerations. Tectonophysics 245(3-4), 121-134 (1995).

32. Yanina, S. V., Rosso, K. M. \& Meakin, P. Defect distribution and dissolution morphologies on low-index surfaces of $\alpha$-quartz. Geochim. Cosmochim. Acta 70(5), 1113-1127. https://doi.org/10.1016/j.gca.2005.11.019 (2006).

33. Benedová, S. \& Leichmann, J. Experimental study of anisotropy of quartz dissolution and its role in fluid migration in rocks. Acta Geodynamica et Geomaterialia 13(2), 193-200. https://doi.org/10.13168/AGG.2016.0001 (2016).

34. Ali, A. M., Yahya, N., Mijinyawa, A., Kwaya, M. Y. \& Sikiru, S. Molecular simulation and microtextural characterization of quartz dissolution in sodium hydroxide. J. Pet. Explor. Prod. Technol. 10, 2669-2684. https://doi.org/10.1007/s13202-020-00940-2 (2020).

35. Kennedy, G. C. A portion of the system silica-water. Econ. Geol. 45, 629-653 (1950).

36. Hippert, J. F. Microstructures and c-axis fabrics indicative of quartz dissolution in sheared quartzites and phyllonites. Tectonophysics 229(3-4), 141-163. https://doi.org/10.1016/0040-1951(94)90026-4 (1994).

37. Takeshita, T. \& Hara, I. c-Axis fabrics and microstructures in a recrystallized quartz vein deformed under fluid-rich greenschist conditions. J. Struct. Geol. 20(4), 417-431. https://doi.org/10.1016/S0191-8141(97)00108-9 (1998).

\section{Acknowledgements}

We thank Gert Kastelein, Aad Jongerius, Eimert de Graaf, Colin Peach, Hans de Bresser and Bas den Brok for their support, encouragement and discussions. This work was sponsored by Shell and carried out at the HighPressure High-Temperature Laboratory of the department of Earth Sciences, Utrecht University, The Netherlands. 
ARN acknowledges support from the ERC through starting grant SEISMIC (335915) and from NWO through a VIDI grant (854.12.011). We thank two anonymous reviewers for their comments and the Editorial Board member Zheshuai Lin for handling our paper. This paper is dedicated to the memory of Professor Henk Zwart, professor in Structural Geology at Utrecht University and strong supporter of experimental research in rock deformation.

\section{Author contributions}

P.M.S. and C.J.S devised the original experiments, P.M.S. performed the experiments and microstructural analyses, A.R.N. prepared Figs. 1-6. All authors discussed the observations and interpretations and reviewed the manuscript.

\section{Competing interests}

The authors declare no competing interests.

\section{Additional information}

Supplementary Information The online version contains supplementary material available at https://doi.org/ 10.1038/s41598-021-94376-1.

Correspondence and requests for materials should be addressed to A.R.N.

Reprints and permissions information is available at www.nature.com/reprints.

Publisher's note Springer Nature remains neutral with regard to jurisdictional claims in published maps and institutional affiliations.

(c) (i) Open Access This article is licensed under a Creative Commons Attribution 4.0 International License, which permits use, sharing, adaptation, distribution and reproduction in any medium or format, as long as you give appropriate credit to the original author(s) and the source, provide a link to the Creative Commons licence, and indicate if changes were made. The images or other third party material in this article are included in the article's Creative Commons licence, unless indicated otherwise in a credit line to the material. If material is not included in the article's Creative Commons licence and your intended use is not permitted by statutory regulation or exceeds the permitted use, you will need to obtain permission directly from the copyright holder. To view a copy of this licence, visit http://creativecommons.org/licenses/by/4.0/.

(C) The Author(s) 2021 